\title{
TRADUÇÃO DA NOVELETA “ICH”, DO AUTOR AUSTRÍACO ARTHUR SCHNITZLER
}

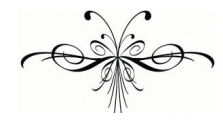 \\ Alice Leal, ANDREA LAUCKNER, \\ ARMIN INNERHOFER, KATHARINA GSCHWENDNER
}

tradução que o leitor está prestes a ler foi realizada como parte
da disciplina intitulada "Tradução Literária" ("Literarisches
Übersetzen"), oferecida, no semestre de verão de 2011, pelo Departamento de Português do Centro de Estudos da Tradução ("Zentrum für Translationswissenschaft") da Universidade de Viena, como parte do curso de mestrado em tradução literária. O projeto, levado a cabo pelos estudantes Andrea Lauckner, Armin Innerhofer e Katharina Gschwendner, foi coordenado pela leitora brasileira Alice Leal.

No presente trabalho serão apresentados alguns aspectos que julgamos relevantes quanto à tradução, um conjunto de impressões e elementos que, juntos, deverão nortear a leitura do conto. Tais impressões e elementos serão expostos da seguinte forma. As duas primeiras e mais curtas seções deste trabalho serão dedicadas ao contexto em que a tradução foi realizada e à escolha do texto, respectivamente. A seção 3, um pouco mais extensa, trará algumas curiosidades quanto ao autor do conto e ao conto em si. Também de mais fôlego, a parte 4 incluirá os aspectos que nortearam nosso projeto de tradução ${ }^{1}$. Por fim, a seção 5 será dedicada às dificuldades encontradas no processo de tradução. Algumas considerações finais fecharão, então, o presente texto.

\section{Do Contexto}

Todos os estudantes que participaram do projeto o fizeram apenas como voluntários, já que as ênfases dos seus cursos não são a tradução literária, mas sim a tradução técnica, os estudos literários e a interpretação. Sendo assim, para os estudantes o projeto foi uma porta de entrada ao mundo da tradução literária, seja para saciar um interesse já pré-existente, ou para explorar uma curiosidade com relação a esse tipo de trabalho.

Além disso, vale ressaltar que todos os estudantes trabalham com o português como segunda ou terceira língua, de modo que a tradução para a língua portuguesa representou um desafio a mais. É importante apontar ainda que os três tradutores falam a variante europeia da língua portuguesa.

\footnotetext{
${ }^{1}$ Para mais informações quanto ao conceito de projeto de tradução subentendido aqui, vide LEAL (2007).
} 


\section{Da Escolha do Texto}

Como nosso objetivo era produzir um texto para publicação, concordamos que deveríamos escolher uma obra que, de alguma forma, representasse a Áustria. Ademais, havia a preocupação de que o texto não oferecesse numerosas dificuldades de tradução - visto que se tratava de um primeiro trabalho de tradução literária para os alunos. De todo modo, o nosso principal desejo era que o texto possuísse características que revelassem um pouco da Áustria - sua língua, cultura e costumes. Daí o interesse na obra do vienense Arthur Schnitzler (1862 - 1931), um dos mais aclamados escritores austríacos de todos os tempos. Por fim, outro fator que contribui para a escolha foi o fato de se tratar de uma tradução inédita.

\section{Do Texto}

Schnitzler escreveu “Ich" (SCHNITZLER [1961] 2006, 304-311) já no fim da vida, no ano de 1927. Histórias como "Ich" lembram muito bem a curiosa relação entre o autor austríaco e Sigmund Freud, seu contemporâneo. De acordo com Andrew Wisely, Freud costumava evitar Schnitzler e seus textos: "O fato de ele [Freud] sistematicamente evitar encontrar-se com Schnitzler era uma tentativa de esquivar-se do choque causado pelo subitamente familiar, visto que vinha notando em Schnitzler, já há um bom tempo, aqueles aspectos de si mesmo que, seja por escolha própria ou por acaso, não haviam sido desenvolvidos (WISELY 2004, 122) ${ }^{23}$. De fato, sempre houve discussão, no campo da psicanálise, quando à originalidade das ideias de Freud, e o pai da psicanálise não hesitava em questionar a própria noção de originalidade, alegando que tudo que tomamos por "original" tem raízes profundas, e que é justamente tarefa da psicanálise tentar "resgatar" essas "raízes" (idem, 125-126). Houve inúmeros casos em que Freud foi "acusado" de inspirar-se em personagens do contemporâneo austríaco para elaborar suas teorias e métodos; de maneira similar, não raros foram os casos em que Schnitzler e seus personagens foram interpretados como respostas - às vezes positivas, às vezes negativas - às teorias e métodos freudianos (idem, 122-144) ${ }^{4}$.

No conto ou noveleta em questão o aspecto que mais nos salta aos olhos é a relação do personagem com a linguagem, não tanto por um viés psicanalista - para cujo desenvolvimento nos falta conhecimento da área -, mas sim sob o ponto de vista da linguagem em si, assim como da relação entre língua e realidade. Não pretendendo aqui fazer uma análise detalhada do conto e de suas possíveis implicações, gostaríamos apenas de ressaltar que o sentimento de perplexidade e alívio que o protagonista de "Ich" constantemente vivencia diante do funcionamento da sua própria língua é o que mais nos fascina na história.

\footnotetext{
2 "His [Freud's] long avoidance of meeting Schnitzler was an attempt to avoid the shock caused by the suddenly familiar, because he had been noticing in Schnitzler for some time those aspects in himself that had been left undeveloped, whether by choice or circumstance"

3 A presente tradução é mais uma tradução documento do que instrumento ("documentary" e "instrumental" - vide NORD [1988] 2005, 80-81), já que somente esse excerto foi traduzido sem se levar em consideração o restante do texto.

4 Àqueles que se interessarem no assunto, a dissertação de mestrado de Vera Regina Santos Cardoni, defendida em 2003 na Universidade Federal do Rio Grande do Sul, analisa a questão a fundo (CARDONI 2003).
} 
Não seria essa também a reação de todo tradutor ou intérprete diante do fenômeno da linguagem? De todo leitor ou falante, em última análise? Não seria a linguagem uma fonte infinita de espanto, em função tanto de seu caos inerente quanto de sua promessa de regularidade? ${ }^{5}$

De acordo com Michael Scheffel, autor do posfácio da obra da qual retiramos a noveleta (SCHEFFEL [1961] 2006, 385-394), "Ich" parece dialogar com a carta fictícia do também austríaco Hugo von Hofmannsthal, escrita em 1902 e intitulada "Ein Brief", ou também "Brief des Lords Chandos an Francis Bacon". A obra do contemporâneo de Schnitzler aborda justamente o que Scheffel chama de "tota [l] Zerfall der Sprache" (idem, 392), ou "decadência" ou "ruína da língua", diagnosticada por Lord Chandos:

Já não conseguia mais contemplá-los [os homens e as ações] através do olhar simplista oriundo do costume. Tudo se fragmentava em pedaços, e os pedaços, em mais pedaços, de modo que nada mais se deixava abranger por um só conceito. Palavras soltas flutuavam ao meu redor; aglutinavam-se em olhos que me encaravam, e a mim só me resta também fitá-los. Vértebras é o que são, e contemplá-las todas me dá vertigem; elas se contorcem sem cessar e, através delas, só se chega ao nada. (HOFMANNSTHAL 1902) ${ }^{6} 8$.

leitor (idem):

Aqui, Lord Chandos oferece um exemplo específico para satisfazer seu

Um regador, um rastelo abandonado no campo, um cão ao sol, um cemitério modesto, um aleijado, uma fazendola - tudo isso pode tornar-se receptáculo da minha epifania. Cada um desses itens, bem como milhares de outros semelhantes - dos quais normalmente se desvia o olhar por pouco caso natural -, pode, em um dado momento (cujo surgimento não depende em nada de mim), subitamente adquirir marcas tão sublimes e comoventes que, para exprimi-lo, nenhuma palavra do mundo parece suficiente9 10 .

Para Scheffel, essa problemática em torno da relação entre linguagem e realidade, abordada por Lord Chandos em sua carta, é levada ad absurdum no texto de Schnitzler (SCHEFFEL [1961] 2006, 392-393), e é justamente essa problemática que tanto nos fascina.

De todo modo, além do gosto por esse conto em particular, sentimos que o texto oferece elementos que podem despertar o interesse do leitor quanto

${ }^{5} \mathrm{O}$ caos subentendido aqui ficará mais claro com a leitura do conto.

${ }^{6}$ O texto de Hofmannsthal encontra-se disponível online por meio do projeto Gutenberg (http://gutenberg.spiegel.de/buch/997/1 - último acesso em junho de 2011).

${ }^{7}$ Es gelang mir nicht mehr, sie [den Menschen und Handlungen] mit dem vereinfachenden Blick der Gewohnheit zu erfassen. Es zerfiel mir alles in Teile, die Teile wieder in Teile und nichts mehr ließ sich mit einem Begriff umspannen. Die einzelnen Worte schwammen um mich; sie gerannen zu Augen die mich anstarrten und in die ich wieder hineinstarren muß: Wirbel sind sie, in die hinabzusehen mich schwindelt, die sich unaufhaltsam drehen und durch die hindurch man ins Leere kommt.

${ }^{8}$ Vide nota 3 acima.

${ }^{9}$ Eine Gießkanne, eine auf dem Feld verlassene Egge, ein Hund in der Sonne, ein ärmlicher Kirchhof, ein Krüppel, ein kleines Bauernhaus, alles dies kann das Gefäß meiner Offenbarung werden. Jeder dieser Gegenstände und die tausend anderen ähnlichen, über die sonst ein Auge mit selbstverständlicher Gleichgültigkeit hinweggleitet, kann für mich plötzlich in irgendeinem Moment, den herbeizuführen auf keine Weise in meiner Gewalt steht, ein erhabenes und rührendes Gepräge annehmen, das auszudrücken mir alle Worte zu arm scheinen.

${ }^{10}$ Vide nota 3 acima. 
à cidade de Viena. Dominando todo o eixo espacial da noveleta (assim como toda a trajetória de Schnitzler), Viena aparece nos nomes das ruas, dos parques, dos bairros e distritos. A cultura tipicamente vienense também não fica de fora, aparecendo em nuances do comportamento dos personagens, tais como a ida à ópera, os passeios de domingo, a ida ao café da esquina para ler o jornal, o uso do bonde como meio de transporte e o apego à família.

No que concerne à linguagem do conto, é curioso que incontáveis trechos soam como conversas que poderiam estar se desenrolando neste exato momento, em algum canto de Viena. Sobretudo nos casos em que o uso de fluxo de consciência é mais patente, a profusão de expressões como "bestimmt", "ja", "eben", "ganz genau" e "natürlich", por exemplo, tornam o texto informal e contemporâneo. Há momentos, contudo, em que o leitor é lembrado de que se trata de um texto de quase 100 anos - os vocábulos de origem francesa, como "Rayon", "Assemblé" e "Entrée", bem como outros vocábulos que, hoje em dia, soam antigos, como por exemplo "Diwan", "genachtmahlt" e "Advokat". Do ponto de vista dos acontecimentos, porém, não há praticamente nada que torne o texto "datado"; com efeito, tudo o que se narra poderia muito bem acontecer nos dias de hoje.

Ainda quando à linguagem do texto, vale alertar o leitor que o texto de Schnitzler é claramente austríaco, vienense até, para sermos mais exatos. Muitas são as expressões que relevam isso; entre elas destacam-se "Gasthaus", "Burschen", "Buben" e "Kredenz", por exemplo.

\section{Do Projeto de Tradução}

Não pretendendo entrar aqui em uma longa discussão teórica, que fique registrado que nos orientamos em muitos dos conceitos discutidos em LEAL (2007), principalmente com relação à ideia, inspirada sobretudo no trabalho de Hans J. Vermeer, de que não há uma tradução correta de um texto, mas sim uma série de projetos ou encargos de tradução ${ }^{11}$ possíveis, todos potencialmente adequados.

Nosso projeto teve início através do estudo do conto com a ajuda do modelo de análise textual orientada à tradução de Christiane Nord (NORD [1988] 2005, LEAL 2005). Embora não tenhamos considerado todos os fatores recomendados por Nord, sentimos que o modelo nos auxiliou a construir uma rede de elementos a serem levados em conta no ato tradutório. O que se seguiu à análise com base no modelo Nord foi a tradução de trechos da noveleta, realizada individualmente pelos estudantes. Essas traduções foram discutidas e comentadas também individualmente, depois refeitas e mais uma vez discutidas, e as-

\footnotetext{
${ }^{11}$ Vide nota 1 acima. Distinguimos aqui entre "encargo" e "projeto de tradução" da seguinte forma. O encargo de tradução refere-se à noção de "Übersetzungsauftrag" de Vermeer, comumente traduzida como "translation commission", em inglês. Àqueles que quiserem explorar mais o conceito e que não dominarem a língua alemã, sugerimos o estudo do seguinte artigo: VERMEER (2000). Já o "projeto de tradução", por sua vez, enfatiza o caráter autônomo do trabalho de tradução naquelas situações em que o iniciador do trabalho de tradução e o tradutor são a mesma pessoa. Para mais informações quanto à noção de "iniciador", vide NORD ([1988] 2005); para mais informações quanto à noção de "projeto de tradução", vide também CARDOZO (2004).
} 
sim sucessivamente, até serem reunidas em uma versão única para debate coletivo e padronização ${ }^{12}$.

Como um dos elementos norteadores do nosso projeto foi o desejo de despertar o interesse do leitor por Viena, a inserção de notas de rodapé e o uso de palavras estrangeiras foi consequência natural do nosso intuito. Esperamos, assim, causar estranheza no leitor, lembrando-o aqui e ali que a história não se passa no Brasil, e que não foi escrita por um brasileiro. Pode-se dizer, ademais, que essa estratégia também tem a ver com o fato de o texto de Schnitzler ser marcadamente austríaco. Em vez de tentarmos "produzir" um "sotaque" reconhecível de língua portuguesa no texto, optamos por fazê-lo soar estrangeiro de vez em quando, diferente do que o provável leitor alvo do presente periódico consideraria "padrão".

Em suma, com relação ao nosso projeto de tradução, se trouxermos à mente a máxima de Schleiermacher ${ }^{13}$, podemos dizer que queremos que o leitor vá até o autor, e não o contrário. Visto que nem o eixo temporal, nem outros elementos intra e extratextuais (NORD [1988] 2005) causaram dificuldades substanciais, exigindo uma postura tradutória sistemática, não teríamos grandes considerações adicionais a fazer quanto ao projeto de tradução.

\section{Das Dificuldades}

Como já mencionado anteriormente, a própria escolha desse texto em particular refletiu a busca por uma obra que não oferecesse grandes dificuldades tradutórias, permitindo, assim, que os alunos pudessem exercitar seus dotes de tradutores literários pela primeira vez com um pouco mais de conforto. No entanto, vale apontar que a estrutura frasal utilizada por Schnitzler representou um desafio na tradução. A sintaxe do alemão permite a concatenação de inúmeras orações coordenadas, inclusive com sujeitos e assuntos completamente distintos. Os falantes de alemão podem, por exemplo, analisar o seguinte trecho de "Ich", que ilustra muito bem a questão:

Dann kam ein einfaches, wohlzubereitetes Mittagessen, die Kinder saßen dabei und waren brav und hübsch, der Bub erzählte von der Schule, die Mutter von einem Spaziergang mit der Kleinen, ehe sie den Großen von der Schule abgeholt, und der Vater berichtete allerlei von geringfügigen Erlebnissen, die sich im Warenhaus zugetragen, von neuen Créationen, Sendungen aus Brünn, erwähnte die besondere Trägheit des Chefs, der meist erst um zwölf im Geschäft erschien, sprach von irgendeiner komischen Erscheinung unter den Kunden, von einem eleganten Herrn, der weiß Gott durch welcher Zufall sich in der Vorstadtgeschäft verirrt, sich zuerst etwas hochnäsig benommen, dann aber von irgendeiner Krawattenmuster gerade zu entzückt gewesen, erzählte

\footnotetext{
${ }^{12}$ Talvez valha a pena mencionar que excertos da tradução, já na fase final do projeto, foram lidos pelos alunos do curso em questão na "Leseabend", ou "Noite de Leituras", organizada semestralmente no Zentrum für Translationswissenschaft e dedicada à leitura, predominantemente de textos literários, traduzidos ou produzidos pelos alunos de bacharelado e mestrado. A participação nesse evento contribuiu com o projeto, já que a leitura em voz alta e a resposta do público - falante de português - ajudaram na fase de revisão do texto.

${ }^{13}$ No original de Schleiermacher, de 1813, lê-se "Entweder der Uebersetzer läßt den Schriftsteller möglichst in Ruhe, und bewegt den Leser ihm entgegen; oder er läßt den Leser möglichst in Ruhe und bewegt den Schriftsteller ihm entgegen". Na tradução de Margarete von Mühlen Poll, temos o seguinte: "Ou o tradutor deixa o autor em paz e leva o leitor até ele; ou deixa o leitor em paz e leva o autor até ele" (SCHLEIERMACHER 2001, 43-44).
} 
von Fräulein Elly, die wieder einmal einen neuen Verehrer hatte, aber ihn ging das eigentlich nichts an, sie war Verkäuferin in der Abteilung für Damenschuhe (SCNHITZLER [1961] 2006, 304).

Já em português, estruturas assim são menos comuns, para não dizer praticamente inexistentes. Todavia, há que se considerar ainda que, em alemão, frases mais curtas também são largamente utilizadas, de modo que a inserção de frases extremamente extensas acaba por marcar o estilo de determinados trechos do conto - estilo este que permeia toda a obra de Schnitzler. Sendo assim, em vez de "quebrar" as longas frases, salpicando pontos-finais aqui e ali, optamos por utilizar pontos-e-vírgulas e travessões - recursos aos quais Schnitzler raramente recorre, mas que funcionam bem em português e mantêm a sensação de frases longas intercaladas com frases curtas. Aliás, esse mecanismo também foi, em alguma medida, adotado por outros tradutores de Schnitzler, tais como Marijane Lisboa, Günther H. Wetzel e Sérgo Tellaroli (vide SCHNITZLER 1996, 1999 e 2000).

\section{Considerações Finais}

Esperamos que leitor aprecie a leitura da tradução. Além disso, esperamos que trabalhos como este estimulem a publicação de mais traduções brasileiras da obra de Schnitzler - que, por enquanto, limitam-se a um número modesto $^{14}$. Aliás, pelo que nossa pesquisa pôde revelar, não há traduções dessa noveleta para o português - nem para o inglês, e nem tampouco para o francês.

Como já mencionado acima, nossa tradução reflete um intuito e um ponto de vista particular. Portanto, seria interessante saber como outros tradutores vislumbram a tradução desse mesmo conto. Ademais, vale ressaltar que sabemos que o presente projeto representa nosso primeiro voo no universo da tradução literária, de modo que críticas e comentários são mais que bem-vindos.

${ }^{14}$ Verificamos que sua prosa mais curta e teatro foram pouco traduzidos para o português do Brasil. As traduções de sua obra que encontramos foram:

SCHNITZLER, Arthur. Contos de Amor e Morte (traduzido por George Sperber). São Paulo, Cia. das Letras, 1987.

. Senhorita Else [traduzido por Marijane Lisboa]. Rio de Janeiro, Paz e Terra S.A., 1996.

. O retorno de Casanova [traduzido por Günther H. Wetzel]. São Paulo, Cia. das Letras, 1999 .

- Breve Romance de Sonho [traduzido por Sérgo Tellaroli]. São Paulo, Cia. das Letras, 2000

Aurora [traduzido por Marcelo Backes]. São Paulo, Boitempo Editorial, 2001.

- A Senhorita Beate e seu filho [traduzido por Marcelo Backes]. Porto Alegre, L\&PM Editores, 2001.

- Doutor Grasler - Médico das Termas [traduzido por Marcelo Backes]. São Paulo, Mercado Aberto, 2002. cord, 2008.

- Crônicas de uma Vida de Mulher [traduzido por Marcelo Backes]. São Paulo, Re-

O Médico das Termas [traduzido por Marcelo Backes]. São Paulo, Record, 2011.

2011.

- O Caminho para a Liberdade [traduzido por Marcelo Backes]. São Paulo, Record, 
Alice Leal

alice.leal@univie.ac.at

Universidade de Viena

\section{Referências bibliográficas}

Cardoni, Vera R. Santos: A Estética da Transitoriedade: Arthur Schnitzler e Sigmund Freud. Porto Alegre, 2003. 112 páginas. Dissertação (Mestrado em Literatura Comparada). Programa de Pós-Graduação em Letras da Universidade Federal do Rio Grande do Sul.

Cardozo, Mauricio M.: Solidão e Encontro: Prática e Espaço da Crítica de Tradução Literária. São Paulo, 2004. 174 páginas. Tese (Doutorado em Letras). Departamento de Letras Modernas da Faculdade de Filosofia, Letras e Ciências Humanas da Universidade de São Paulo.

LeAL, Alice: Funcionalismo e Tradução Literária: O Modelo de Christia-ne Nord em Três Contos Ingleses Contemporâneos. Curitiba, 2005. 110 páginas. Monografia (Bacharelado em Letras Inglês-Português, com ênfase nos Estudos da Tradução,). Setor de Ciências Humanas, Letras e Artes da Universidade Federal do Paraná.

- Funcionalismo e Tradução Literária: Quatro Projetos para a Tradução de The Years, de Virginia Woolf. Florianópolis, 2007. 135 páginas. Dissertação (Mestrado em Estudos da Tradução - História, Crítica e Teoria da Tradução). Centro de Comunicação e Expressão da Universidade Federal de Santa Catarina.

NorD, Christiane [1988]: Text Analysis in Translation: Theory, Methodo-logy, and Didactic Application of a Model of Translation-oriented Text Analysis [transl. Christiane Nord and Penelope Sparrow]. Amsterdam, Atlanta, Rodopi, 2005.

SCHEFFEL, Michael [1961]: Nachwort in Arthur Schnitzler: Traumnovelle und andere Erzählungen. Frankfurt am Main, S. Fischer Verlag $\mathrm{GmbH}$, 2006.

SCHLEIERMACHER, Friedrich: "Ueber die verschiedenen Methoden des Uebersetzens" ("Sobre os Diferentes Métodos de Tradução" - trad. Margarete von Mühlen Poll - org. Werner Heidermann). Florianópolis, NUT, UFSC, 2001.

Schnitzler, Arthur: Senhorita Else [trad. Marijane Lisboa]. Rio de Janeiro, Paz e Terra S.A., 1996.

. O Retorno de Casanova [trad. Günther H. Wetzel]. São Paulo, Cia. das Letras, 1999.

- Breve Romance de Sonho [trad. Sérgio Tellaroli]. São Paulo, Cia. das Letras, 2000.

. [1961]. Arthur Schnitzler: Traumnovelle und andere Erzählungen. Frankfurt am Main, S. Fischer Verlag GmbH, 2006.

VermeER, Hans J. [1989]: 'Skopos and Commission in Translational Action'. In: The Translation Studies Reader. London and New York, Routledge, 2000, 221-232.

Wisely, Thomas: Arthur Schnitzler and Twentieth Century Criticism. New York, Camden House, 2004. 


\section{Ich \\ Novellette}

Bis zu diesem Tage war er ein völlig normaler Mensch gewesen. Früh um sieben Uhr stand er auf, möglichst geräuschlos, um seine Frau nicht zu stören, die gern etwas länger schlief, trank eine Tasse Kaffee, küßte den achtjährigen Buben auf die Stirn, der in die Schule mußte, und bemerkte scherzhaft seufzend $\mathrm{zu}$ der sechsjährigen Marie: $>$ Ja, nächstes Jahr kommst du auch dran $<{ }^{15}$. Während er noch mit den Kleinen scherzte, pflegte seine Frau einzutreten, und es gab eine harmlose Unterhaltung, manchmal sogar recht vergnügt und immer ruhig, denn es war eine gute Ehe, ohne Mißverständnisse und ohne Unzufriedenheiten, sie hatten sich gegenseitig nichts vorzuwerfen. Um ein Uhr kam er aus dem Geschäft nach Hause, nicht einmal sonderlich müd, denn was er zu tun hatte, war weder sehr anstrengend noch sehr verantwortungsvoller Natur; er war Abteilungsvorstand, sogenannter Rayonchef in einem Warenhaus mäßigen Ranges in der Währingerstraße. Dann kam ein einfaches, wohlzubereitetes Mittagessen, die Kinder saßen dabei und waren brav und hübsch, der Bub erzählte von der Schule, die Mutter von einem Spaziergang mit der Kleinen, ehe sie den GroBen von der Schule abgeholt, und der Vater berichtete allerlei von geringfügigen Erlebnissen, die sich im Warenhaus zugetragen, von neuen Créationen, Sendungen aus Brünn, erwähnte die besondere Trägheit des Chefs, der meist erst um zwölf im Geschäft er-

\section{Eu \\ Noveleta}

Até aquele dia fora um homem absolutamente normal. Às sete da manhã, levantava-se o mais silenciosamente possível, para não perturbar a esposa que gostava de dormir até mais tarde; bebia uma xícara de café, beijava o filho - que tinha de ir à escola na testa e, com um suspiro, dizia jocosamente à Marie, que tinha seis anos: "Pois é, no ano que vem vai ser a sua vez." Enquanto ele ainda brincava com a menina, a esposa costumava entrar; seguiase uma conversa inofensiva, às vezes até alegre e sempre tranquila, pois o casamento deles era bom, sem mal-entendidos e sem infelicidade, sem acusações recíprocas. À uma hora regressava da loja para casa, até não muito cansado porque o que ele tinha de fazer não era um trabalho nem cansativo nem repleto de responsabilidade - era chefe de departamento, o assim chamado chefe de $R a$ $y{ }^{17}$ em uma loja de departamentos de qualidade mediana na Währingerstrasse ${ }^{18}$. Depois vinha um almoço simples, bem-feito; os filhos, bonzinhos e arrumados, sentavam-se com ele à mesa; o menino contava da escola; a mãe, do passeio que fizera com a filha antes de buscar o pequeno na escola; e o pai falava de mil acontecimentos insignificantes na loja, de novas criações, dos artigos que lhes foram expedidos de Brno, na República Checa; contava do chefe preguiçoso que, na maioria das vezes, aparecia na loja só por volta do meio-dia; falava de um cliente estranho, de um homem ele-

\footnotetext{
${ }^{15}$ Vide nota 16 abaixo.
} 
schien, $[\text { sprach }]^{16}$ von irgendeiner komischen Erscheinung unter den Kunden, von einem eleganten Herren, der weiß Gott durch welchen Zufall sich in das Vorstadtgeschäft verirrt, sich zuerst etwas hochnäsig benommen, dann aber von irgendeinem Krawattenmuster gerade zu entzückt gewesen, erzählte von Fräulein Elly, die wieder einmal einen neuen Verehrer hatte, aber ihn ging das eigentlich nichts an, sie war Verkäuferin in der Abteilung für Damenschuhe.

Dann legte er sich für ein halbes Stündchen hin, blickte flüchtig in eine Zeitung; um halb drei war er wieder im Geschäft, es gab viel zu tun, besonders zwischen vier und sechs, er konnte sich völlig den Kunden widmen, zu Hause ging ja alles den gewohnten Gang, die Frau ging mit den Kindern spazieren oder die verheiratete Schwägerin kam zu Besuch oder ihre Mutter; er traf sie manchmal noch zu Hause an.

Gegen acht aß man zu Abend; die Kinder waren schon gante que sabe Deus por qual razão acabou indo parar na loja e que, no início, comportara-se um pouco presunçosamente, mas depois ficou até entusiasmado com a estampa de uma gravata qualquer; contava da Fräulein ${ }^{19}$ Elly que outra vez tinha um novo admirador se bem que isso não era da sua conta, dado que ela era vendedora no departamento de calçados femininos.

Depois se deitava por meiahorinha, dava uma olhada rápida no jornal; às duas e meia estava de volta à loja, havia bastante coisa para fazer, sobretudo entre as quatro e as seis; podia dedicar-se completamente aos clientes, pois em casa tudo corria como de costume; a esposa levava os filhos para passear, ou a cunhada casada vinha à casa, ou então a mãe dela - às vezes ainda estavam lá quando ele voltava do trabalho.

Jantava-se por volta das oito; os filhos eram colocados na

17 "Chefe de Rayon" é uma expressão antiga e significa "chefe do departamento". Palavras desse tipo, isto é, palavras de origem francesa, na primeira metade do século XX, eram usadas muito frequentemente na sociedade vienense. Hoje em dia, somente pessoas de idade fazem uso dessas palavras.

${ }^{18}$ A Währingerstrasse é a rua principal do $9^{\circ}$ distrito de Viena, um distrito nobre e rico perto do centro da cidade. Nesse distrito moraram, por exemplo, Siegmund Freud (de 1891 a 1938) e Franz Schubert (de 1797 a 1801).

${ }^{16} \mathrm{O}$ editor do volume do qual o presente texto foi retirado incluiu, entre colchetes, palavras que pareciam estar faltando no original. De acordo com as referências bibliográficas, a versão publicada em 2006 apareceu pela primeira vez em 1968, e foi retirada (presumivelmente com os colchetes) do volume editado mais tarde, em 1997, por Reinhard Urbach, intitulado Entworfenes und Verworfenes. Levando-se em conta a data de produção do texto e a publicação póstuma, pode-se especular que talvez o texto não tenha sido exaustivamente revisado pelo autor - daí a "falta" de algumas palavras. De fato, no seu posfácio, Scheffel refere-se à noveleta ("Ich") "rascunhada" ("entworfene") por Schnitzler (SCHEFFEL [1961] 2006, 392). Vale notar ainda que dois aspectos parecem "incoerentes" no texto, a saber: inicialmente, a esposa do protagonista parece chamar-se "Anna", mas, já no final do texto, o narrador refere-se a ela como "Marie". Além disso, no início do texto o narrador explica que a filha mais nova do protagonista ainda não vai à escola, enquanto no final ele se refere à ida e à volta de ambos os filhos da escola. Resta saber se essas incoerências aparentes foram ou não propositais - fato que, por sinal, não afeta em nada o texto, mas desperta, de todo modo, curiosidade.

${ }^{19}$ A designação "Fräulein", antigamente usada para o tratamento de senhoras não casadas, vem caindo em desuso durante as últimas décadas. 
früher zu Bett gebracht. An jedem zweiten Samstag erfolgte ein Theaterbesuch, dritte Galerie, dritte oder vierte Reiher, Operette zog er vor, aber zuweilen sah man sich auch ein ernstes Stück an, ein klassisches oder eine Gesellschaftskomödie, und den Beschluß solcher Abende machte ein bescheidenes Restaurant. Die Kinder waren indes in gut Obhut, Frau Wilheim, der kinderlosen Frau des Arztes vom ersten Stock, war es eine recht Freude, so lange in der Wohnung bei den Kleinen $\mathrm{zu}$ wachen, bis die Eltern nach Hause kamen.

Auch an diesem Abend, dem Samstag vor Pfingsten, waren sie im Theater gewesen, das Ehepaar Huber hatte dann im Gasthaus genachtmahlt, und als sie zu Bette gingen, war der Ehegatte so gut aufgelegt gewesen, daß An$\mathrm{na}^{20}$ bemerkte, ob er sie nicht vielleicht mit Frau Constantin verwechsle, die heute die Hauptrolle gespielt und ihm so besonders gut gefallen hatte.

Am nächsten Morgen begab er sich, wie es seine Sonntagsgewohnheit war, auf einen kleinen Ausflug, fuhr mit der Straßenbahn nach Sievering, wanderte auf den Dreimarkstein, wo er einem guten Bekannten begegnete, mit ihm stehenblieb und über das schöne cama antes. A cada dois sábados, tinha lugar uma ida ao teatro, terceira galeria, terceira ou quarta fila; ele preferia as operetas, mas, de vez em quando, assistiam a um espetáculo mais sério, um clássico ou uma comédia de costumes, e terminavam essas noites em um restaurante modesto. Enquanto isso, as crianças ficavam em boas mãos; para a Frau Wilheim, esposa sem filhos do médico que morava no primeiro andar, era até um prazer cuidar dos pequenos no apartamento até que os pais retornassem.

Também naquela noite, no sábado na véspera de Pentecostes, o casal Huber fora ao teatro, ceara em um restaurante típico e, quando se deitaram, o bom humor do esposo era tal, que Anna perguntou-lhe se ele talvez a confundisse com a Frau Constantin, a protagonista de hoje da qual ele tanto gostara.

$\mathrm{Na}$ manhã seguinte partiu, como fazia todos os domingos, para um passeio ${ }^{21}$; pegou o bonde para Sievering ${ }^{22}$, passeou pelo Dreimarkstein $^{23}$, encontrou um conhecido - com quem papeou sobre o bom tempo que fazia - e depois desceu até Neuwaldegg ${ }^{24}$.

\footnotetext{
${ }^{20}$ Vide nota 16 acima.

${ }^{21} \mathrm{O}$ passeio do protagonista pode ser feito também nos dias de hoje. A linha de ônibus 39A termina em Sievering - o bonde tomado pelo protagonista já não existe mais. De lá se segue uma caminhada de aproximadamente três quilômetros até Dreimarkstein. A descida para Neuwaldegg se estende por cerca de quatro quilômetros, sendo que o Schwarzenbergpark fica logo no caminho. Outra opção é seguir a trilha de número 3 (Stadtwanderweg 3 - Hameau) sugerida no site oficial da cidade de Viena que, embora não na mesma ordem, passa pelos mesmos pontos visitados pelo protagonista e se estende por 10,5 quilômetros

(http://www.wien.gv.at/umwelt/wald/freizeit/wandern/wanderweg3.html - último acesso em junho de 2011).

${ }^{22}$ Sievering é uma região no $19^{\circ}$ distrito.

${ }^{23}$ O Dreimarkstein é uma montanha de 454 metros de altura que faz a divisa do $19^{\circ}$ com o $17^{\circ}$ distrito.

${ }^{24}$ Neuwaldegg foi, até 1892 , uma comunidade autônoma que hoje forma parte do $17^{\circ}$ distrito.
} 
Wetter plauderte, dann spazierte er allein hinab nach Neuwaldegg. Er überschritt eine kleine Brücke, wie er es schon hundert Mal vorher getan, die weite große Wiese mit prächtigen Baumgruppen lag vor ihm, die er weiß Gott wie oft gesehen, und sein Blick fiel von ungefähr auf eine roh hölzerne Tafel, die an einem Baum genagelt war und auf der mit großen schwarzen Buchstaben, wie von Kinderhand geschrieben, das Wort $>$ Park $<$ zu lesen stand. Er erinnerte sich nicht, diese Tafel jemals früher gesehen $\mathrm{zu}$ haben. Sie fiel ihm auf, aber er dachte gleich: daß sie immer dagewesen war, man sah es ihr an, daß es eine ganz alte Tafel war. Ja natürlich, dies war ein Park, niemand konnte daran zweifeln, der Schwarzenbergpark war es, Privatbesitz des böhmischen Fürstengeschlechts, aber dem Publikum seit Jahrzehnten freigegeben. Doch da stand nicht Schwarzenbergpark oder Privatbesitz, sondern komischerweise einfach: Park. Man sah doch, daß es ein Park war, niemand konnte daran zweifeln. Er unterschied sich nicht sonderlich von der Umgebung, er war nicht abgeschlossen, es gab kein Entrée, er stand nicht unter besonderen Gesetzen, es war Wald und Wiese und Wege und Bänke, jedenfalls war es ziemlich überflüssig, daß da eine Tafel hing, auf der das Wort $>$ Park $<$ geschrieben stand.

Immerhin mußte es seinen Grund haben. Vielleicht gab es Leute, die nicht so sicher waren, wie er, daß das ein Park war. Vielleicht hielten sie es für ganz gewöhnlichen Wald [an der] ${ }^{27}$ Wie-
Atravessou uma pequena ponte, como já fizera inúmeras vezes; o prado espaçoso, onde se podiam observar portentosos agrupamentos de árvores - que sabe Deus quantas vezes já havia visto - encontrava-se em sua frente quando, por acaso, o seu olhar repousou em uma tábua rústica de madeira pregada em uma árvore, na qual se encontrava escrita, em grandes letras infantis, a palavra "Park". Não se lembrava de jamais haver visto aquela placa. Reparou nela, pensando instantaneamente que sempre houvera ali estado, pois tinha o ar de ser uma tábua bem velha. Claro, era um parque, não havia dúvidas - era o Schwarzenbergpark $^{25}$, propriedade privada da dinastia boêmia, mas aberta ao público há décadas. Porém, ali não estava escrito "Schwarzenbergpark" ou "propriedade privada", mas sim, curiosamente, apenas "Park". Era óbvio que era um parque, não havia dúvidas. Não se distinguia muito do seu entorno, não estava cercado, não havia uma Entrée ${ }^{26}$, nem tampouco vigoravam ali leis especiais; era floresta e prado e caminhos e bancos; em todo o caso, era desnecessário que ali houvesse uma tábua em que se encontrava escrita a palavra "Park".

Isso, sem dúvida, devia ter sua razão de ser. Talvez houvesse pessoas que não tivessem a mesma certeza que ele tinha de que isso era um parque. Talvez pensassem tratar-se de uma simples flo-

\footnotetext{
${ }^{25}$ O Schwarzenbergpark é um parque em Neuwaldegg, no $17^{\circ}$ distrito.

${ }^{26}$ Vide nota 23 acima.

${ }^{27}$ Vide nota 16 acima.
} 
se, wie den Wald und die Wiesen, von denen er eben herunterkam. Denen mußte man es freilich in Erinnerung bringen, daß dies ein Park war. Ein schöner Park übrigens, herrlich - vielleicht gab es Leute, die es für ein Paradies gehalten hätten, wenn die Tafel dort nicht gehangen wäre. Haha, ein Paradies. Und da hätte vielleicht einer sich danach benommen und seine Kleider abgeworfen und öffentliches Ärgernis erregt. Wie sollte ich [denn] ${ }^{28}$ wissen, sagte er auf der Polizei, daß es nur ein Park war und nicht das Paradies. Nun konnte das nicht mehr passieren. Es war höchst vernünftig gewesen, die Tafel dorthin zu hängen. Er begegnete einem Paar, einem nicht mehr sehr jungen, wohlbeleibten Paar, und er lachte so laut, daß sie erschraken und ihn groß ansahen.

Es war noch nicht spät, er setzte sich auf eine Bank. Ja, es war ganz sicher eine, obzwar nicht darauf geschrieben stand, daß es eine Bank war und der Teich drüben, der wohlbekannte, war ganz bestimmt ein Teich - oder ein Weiher - oder ein kleiner See oder ein Meer, ja, es kam nur darauf an, wie man ihn ansah, für eine Eintagsfliege war es wahrscheinlich ein Meer. Für solche Eintagsfliegen sollte man auch eine Tafel aufhängen: Teich. Aber für die Eintagsfliege war es ja eben kein Teich, und nebstbei konnten sie nicht lesen. Nun, wer weiß, dachte er weiter, wir wissen verdammt wenig von den Eintagsfliegen. Da schwirrte eine um ihn. Mittag war es - die war just einen halben Tag alt, vielmehr fünfzig Jahre... im Verhältnis, denn am Abend war sie ja tot. Vielleicht resta ou prado - como a floresta e os prados que acabara de atravessar. Nesse caso, era óbvia a necessidade de se lembrar tais pessoas de que se tratava de um parque. Aliás, um belo parque, maravilhoso - possivelmente haveria quem o tomasse pelo paraíso, não estivesse ali a tábua pendurada. Haha, o paraíso. Talvez houvesse quem tivesse agido nesse sentido, despindo-se e cometendo, assim, um atentado ao pudor. Como poderia eu saber, diria ele na polícia, que era só um parque e não o paraíso? Agora, tal situação jamais poderia acontecer. Colocar a placa ali fora extremamente prudente. Cruzou com um casal corpulento e já não tão jovem, e riu tão alto que estes se assustaram, fitando-o de olhos arregalados.

Ainda não era tarde, sentouse em um banco. Sim, era com certeza um banco, mesmo que não estivesse escrito que se tratava de um banco, e o laguinho ao lado, bem conhecido, era definitivamente um laguinho ou uma lagoa, ou um lago, ou um mar; é, só dependia do ponto de vista - para uma efêmera provavelmente era um mar. Para tais efêmeras também se deveria pendurar uma placa: "laguinho". Só que para as efêmeras não era laguinho coisa nenhuma e, além do mais, não sabiam ler. Mas, quem sabe, continuou pensando, nós sabemos muito pouco sobre as efêmeras. Nesse instante, uma voava ao seu redor. Era meio-dia, então aquela tinha meio-dia de idade, ou seja, cinquenta anos... proporcionalmente, visto que à noite estaria morta. Provavelmente celebraria agora

\footnotetext{
${ }^{28}$ Vide nota 16 acima.
} 
feierte sie soeben ihren fünfzigsten Geburtstag. Und die anderen kleinen Fliegen, die um sie schwirrten, die waren Gratulanten. Ein Geburtstagsfest, dem er beiwohnte. Es war ihm, als säße er sehr lange da und er blickte auf die Uhr. Er war nur drei Minuten da gesessen, ja, dies war bestimmt eine Uhr, wenn auch auf dem Deckel nicht eingegraben stand, daß sie eine war. Aber es konnte ja auch sein, daß er träumte. Dann war das keine Uhr, dann lag er im Bett und schlief und auch die Eintagsfliege war nur ein Traum.

Zwei junge Burschen gingen vorüber. Lachten sie über ihn? Über seine dummen Einfälle? Aber die wußten ja nichts davon. So sicher war das freilich nicht. Es gab ja Gedankenleser. Sehr möglich, daß dieser Junge mit der Hornbrille ganz genau wußte, was in ihm vorging und darüber lachte. Die Frage war nur, ob er Grund dazu hatte, dieser Jüngling mit der Hornbrille? Denn es wäre ja möglich, daß dies Ganze wirklich ein Traum war, dann träumte er auch das Lachen dieses Andern.

Mit einem plötzlichen Entschluß trat er sich selbst mit einem Fuß auf den andern, und zum Überfluß faßte er sich an der $\mathrm{Na}$ se. Er spürte alles ganz genau. Und das wollte er als Beweis für sein Wachsein gelten lassen. Kein sehr zwingender freilich, denn am Ende konnte er auch den Fußtritt und den Griff an die Nase träumen. Aber er wollte sich für diesmal zufrieden geben.

Er machte sich auf den Heimweg, um eins erwartete ihn das Mittagessen. Er fühlte sich sonderbar leicht, er lief geradezu, er schwebte, nicht nur figürlich. mesmo o seu quinquagésimo aniversário. $\mathrm{E}$ as outras mosquinhas que a rodeavam eram os convidados. Uma festa de aniversário à qual ele assistia. Parecia que estava sentado ali já há muito tempo e olhou para o relógio. Estivera ali por apenas três minutos - é, aquilo com certeza era um relógio, ainda que na tampa não estivesse gravado que o era. Só que também poderia dar-se o caso de estar sonhando. Assim, aquilo não seria um relógio, ele estaria deitado na cama, e também a efêmera seria apenas um sonho.

Dois rapazes passaram por ele. Será que se riam dele? Das suas ideias estúpidas? Mas se eles não sabiam delas? Bom, não era assim tão certo que não soubessem. Afinal, existiam leitores de pensamentos. Era bem possível que aquele rapaz de óculos soubesse exatamente o que lhe passava pela cabeça, e disso se ria. A questão era apenas se o jovem de óculos teria motivos para tal? Porque era possível que tudo isso fosse realmente um sonho... então o riso do outro também não passava de um sonho.

Como se decidisse repentinamente, aplicou um pontapé no próprio pé e, como se não bastasse, apalpou o nariz. Sentiu tudo intensamente. Para ele, isso deveria ser prova suficiente de que estava acordado. Nada contundente, entretanto, essa prova; afinal de contas, talvez o pontapé e o toque no nariz também não passassem de um sonho. Decidiu, todavia, dar-se por satisfeito dessa vez.

Tomou, então, o caminho de casa, já que o almoço o esperava à uma hora. Sentia-se estranhamente leve, corria, flutuava de verdade - não só no sentido figurado. A 
Es kam immer ein Bruchteil einer Sekunde, in der keiner seiner Füße den Boden berührte.

Er nahm die Straßenbahn. Die flog noch rascher als er; geheimnisvoll diese elektrische Kraft. Es war halb zwei. Nun feierte die Eintagsfliege ihren fünfundfünfzigsten Geburtstag. Die Häuser rasten an ihm vorbei. So, nun mußte er umsteigen. Er wußte genau, daß er hier umsteigen mußte. Sonderbar, das alles zu wissen. Wie wenn er vergessen hätte, daß er in der Andreasgasse wohnte? Andreasgasse vierzehn, zweiter Stock, Tür zwölf. Bestimmt. Was alles in einem Gehirne Raum hat. Er wußte auch, daß er morgen acht Uhr früh im Geschäfte sein wollte. Er sah es vor sich, er sah die Krawatten, sah jedes Muster. Hier war die blau-rotgestreifte, hier die gesprenkelte, hier die mit dem gelblichen Ton. Er sah sie alle, und er sah auch die Aufschrift über dem Fach, da stand: Halsbinden, obwohl doch jeder wußte, daß es Halsbinden waren. Ganz klug, daß dort an einem Baum die Tafel $>$ Park $<$ hing. Nicht alle Menschen waren so geistesgegenwärtig und scharfsinnig wir er, daß sie ohne weiteres wußten, dies ist ein Park, und dies ist eine Halsbinde.

Er stand vor seiner Wohnungstür. Er hatte weder bemerkt, daß er die Straßenbahn verlassen, noch daß er durch seine Gasse ge- cada troca de passos, havia um momento em que, por uma fração de segundos, nenhum dos seus pés tocava o chão.

Pegou o bonde. O bonde voava ainda mais depressa do que ele - misteriosa, essa tal força elétrica. Era uma e meia. A estas alturas a efêmera celebrava seu quinquagésimo-quinto aniversário. Os edifícios passavam por ele em alta velocidade. Muito bem, agora era hora de trocar de bonde. Ele bem sabia que era exatamente ali que deveria desembarcar. Estranho saber tudo isso. Como será que seria, então, se ele esquecesse que morava na Andreasgasse ${ }^{29}$ ? Andreasgasse, número quatorze, segundo andar, apartamento doze. Sem dúvida. Como há espaço no cérebro para tanta coisa. Ele sabia também que, amanhã cedo, pretendia chegar ao trabalho às oito horas. Ele conseguia vê-las diante de seus olhos, as gravatas, cada uma das estampas. Aqui, as listradas de azul e vermelho; ali, as de bolinhas; lá, as amareladas. Podia vê-las todas, assim como a placa no topo da estante dizendo "Gravatas" - muito embora todos soubessem que se tratavam de gravatas. Muito prudente que houvesse uma placa pendurada naquela árvore dizendo "Park". Nem todos tinham a mesma presença de espírito e a mesma sagacidade que ele, a ponto de saberem, sem maiores indicações, que tal coisa era um parque e que tal coisa era uma gravata.

Encontrava-se agora diante da porta de entrada do seu apartamento. Não percebera nem que descera do bonde, nem que cami-

${ }^{29}$ A Andreasgasse é uma rua curta do $7^{\circ}$ distrito, perpendicular à Mariahilfertrasse, uma das principais ruas de compras de Viena. Foi assim denominada em 1897, em homenagem ao empresário Andreas Ditscheiner. 
gangen, noch daß er durch das Haustor getreten, noch daß er die Treppe hinaufgegangen war. Möglich, daß er hinaufgeflogen war. Man setzte sich zu Tisch. Dies war der Suppentopf, dies waren die Suppenteller, Löffel, Gabel, Messer. Er wußte es von allen ganz genau. Für ihn mußte man keine Bezeichnungen hinschreiben. Er betrachtete alle Gegenstände sehr sorgfältig. Es stimmte. Und er erzählte von der Eintagsfliege, die eben ihren Geburtstag feierte. Sie hatte große Assemblé. Das Wort flatterte durch die Luft. Niemals in seinem Leben hatte er dieses Wort ausgesprochen. Wo kam es her? Wo ging es wieder hin?

Nachmittags konnte er nicht schlafen. Er lag auf dem Diwan im Speisezimmer, niemand war bei ihm. Er nahm sein Notizbuch. Es war bestimmt sein Notizbuch und weder seine Brieftasche noch seine Zigarrentasche, und schrieb auf ein Blatt $>$ Kredenz $<$, auf ein anderes $>$ Schrank $<$, auf ein anderes $>$ Bett $<$, auf ein anderes $>$ Sessel $<$. Das mußte er einige Male schreiben. Dann befestigte er diese Blätter an die Kredenz, an den Schrank, schlich sich ins Schlafzimmer, wo seine Frau ihren Nachmittagsschlummer hielt, und mit einer Stecknadel befestigte er das Blättchen $>$ Bett $<$. Er ging weg, ehe sie aus dem Mittagsschlaf erwacht war. Dann begab er sich in das Kaffeehaus und las Zeitung, vielmehr, er versuchte es nur. All das Gedruckte, das er vor sich sah, erschien ihm verwirrend und beruhigend zugleich. Hier standen Namen, Bezeichnungen, über die ein Zweifel nicht beste- nhara rua acima, nem que atravessara o portão de entrada do edifício, nem tampouco que subira as escadas. Talvez tivesse voado até lá. Sentaram-se à mesa. Isto era uma caçarola, estes eram os pratos fundos, colher, garfo, faca. Conhecia tudo com precisão. Para ele, não eram necessárias placas explicativas. Examinou, cuidadosamente, todas as coisas à sua volta. Tudo certo. Contou, então, da efêmera aniversariante. Tivera

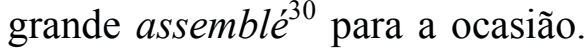
A palavra assemblé tremulou pelo ar. Nunca na vida proferira-a. De onde viera? Aonde iria?

Naquela tarde não conseguiu dormir. Ficou deitado, sozinho, no divã da sala de jantar. Tomou o bloco de anotações. Era de fato seu bloco de anotações, e não sua carteira ou charuteira. Em uma folha escreveu "aparador", em outra, "armário", em mais uma, "cama" e, em uma quarta folha, "cadeira". A última precisou repetir algumas vezes. Afixou, então, uma folha no aparador e outra no armário; pé ante pé, entrou no quarto, onde a esposa tirava seu cochilo vespertino, e afixou, com um alfinete, a folhinha que dizia "cama". Feito isso partiu, antes que a esposa despertasse. Dirigiuse, então, ao café da esquina e pôs-se a ler o jornal, ou melhor, tentou fazê-lo. Todas aquelas letras impressas, que agora tinha diante dos olhos, lhe pareciam, ao mesmo tempo, fontes de confusão e alívio. Havia ali nomes, designações com relação às quais não restava dúvida. Só que as coisas a

\footnotetext{
${ }^{30}$ Vide nota 23 acima. A palavra "asssemblé" significa reunião, do verbo francês "assembler", juntar, reunir.
} 
hen konnte. Aber die Dinge, auf die sich diese Namen bezogen, waren weit. Es war ganz sonderbar zu denken, daß eine Beziehung existierte zwischen irgendeinem Wort, das da gedruckt war, z.B. Theater in der Josefstadt, und dem Haus, das ganz woanders in einer anderen Straße stand. Er las die Namen der Darsteller. Zum Beispiel Dubonet, Advokat - Herr Mayer. Diesen Herrn Dubonet, das war das Allerseltsamste, den gab es gar nicht. Den hatte irgendwer erfunden, aber hier stand sein Name gedruckt. Der Herr Mayer aber, der den Dubonet spielte, der existierte wirklich. Es konnte sein, daß er diesem Herrn Mayer schon oft auf der Straße begegnet war, ohne nur zu ahnen, daß er gerade Herr Mayer war. Er trug ja keine Aufschrift, wenn er auf der Straße spazierenging. Und täglich begegnete er so Hunderten Menschen, von denen er nicht im entferntesten ahnte, woher sie kamen, wohin sie gingen, wie sie hießen, es konnte sein, daß einer von ihnen, kaum um die Ecke, vom Schlag getroffen tot zusammenstürzte. Am nächsten Tag stand es wohl auch in der Zeitung, daß Herr Müller, oder wie er hieß, tot zusammengestürzt sei; er aber, Herr Huber, würde keine Ahnung haben, daß er ihm noch fünf Minuten vor seinem Tode begegnet war. Erdbeben in San Franzisko. Das steht auch hier in der Zeitung. Aber außer diesem Erdbeben, das hier in der Zeitung stand, gab es doch ein ganz anderes, das wirkli- que esses nomes se referiam eram vastas. Parecia-lhe absolutamente insólito que existisse uma relação entre cada palavra ali impressa, por exemplo, "Theater in der Josefstadt"31, e o edifício, que por sua vez se localizava alhures, em uma rua completamente diferente. Percorreu os nomes dos atores com os olhos. Por exemplo, Advogado Dubonet - Herr Mayer. O caso desse tal advogado Dubonet era o mais curioso de todos, pois ele não existia. Alguém o inventara, mas mesmo assim aqui estava seu nome impresso. Já o Herr Mayer, que interpretava o papel do advogado Dubonet, esse existia de verdade. Era bem possível que ele já tivesse até cruzado com esse tal Herr Mayer na rua, sem atinar, no entanto, que se tratava justamente do Herr Mayer. Afinal, ele não andava por aí portando placas explicativas. Diariamente cruzava com centenas de pessoas de cuja proveniência e destino ele não tinha a menor das ideias - dos nomes ainda menos; poderia inclusive dar-se o caso de que uma dessas pessoas, acometida por um derrame, caísse morta a míseros metros de distância dele. No dia seguinte, tal fato poderia muito bem aparecer também no jornal que um tal Herr Müller, ou seja lá qual fosse seu nome, caiu morto na rua; só que ele próprio, o Herr Huber, não teria a mínima ideia que, cinco minutos antes de morrer, o defunto cruzara com ele. Terremoto em São Francisco. Isso também está aqui no jornal. Mas

${ }^{31} \mathrm{O}$ Theater in der Josefstadt, localizado no homônimo $8^{\circ}$ distrito, foi fundado em 1788 e é, portanto, o teatro vienense mais antigo ainda em funcionamento. Beethoven, Wagner e Johann Strauss I são alguns dos ilustres nomes que tiveram apresentações lá. Além disso, Johann Nestroy, por exemplo, estreou no teatro como ator e dramaturgo (1829), e figuras como Max Reinhardt e Hugo von Hofmannsthal tiveram diversas apresentações e estreias lá. Atualmente o teatro oferece uma programação variada, com clássicos e produções contemporâneas - muitas estreantes. 
che. Dann fiel sein Blick auf Inserate, Ankündigungen. Es gab Geschäfte, die ihm bekannt waren. Bei diesem oder jenem Inserat stieg zu gleicher Zeit ein Gebäude vor ihm auf, in dem er jenes Geschäft wußte oder vermutete. Andere aber blieben tot. Er sah nichts als die gedruckten Buchstaben.

Er blickte auf. In der Kassa saß das Fräulein Magdalene. Ja, so hieß sie. Es war ein etwas außergewöhnlicher Name für eine Kaffeehauskassierin. Er hörte nur immer den Namen von den Kellnern ausgesprochen. Er selbst hatte nie das Wort an sie gerichtet. Da saß sie, etwas dick, nicht mehr ganz jung, immerfort beschäftigt. Niemals hatte er sich um sie im geringsten gekümmert. Jetzt plötzlich, nur weil er sie zufällig angesehen, trat sie aus all den andern hervor. Das Kaffeehaus war ziemlich gefüllt, mindestens sechzig, achtzig, vielleicht hundert Menschen waren da. Höchstens von zweien oder dreien kannte er den Namen. Unbegreiflich, daß diese gleichgültige Kassierin plötzlich die wichtigste Person war. Einfach dadurch, daß er sie ansah. Von allen andern wußte er gar nichts, alle waren sie Schatten. Auch seine Frau, seine Kinder, alle waren sie geradezu nichts im Verhältnis zu Fräulein Magdalene. Die Frage war jetzt nur, was für einen Zettel man ihr ankleben sollte. Magdalene? Fräulein Magdalene? Oder Sitzkassierin? Jedenfalls war es além deste terremoto descrito aqui no jornal, havia ainda outro, completamente diferente - o verdadeiro. Seu olhar vagueou, então, por anúncios e propagandas. Havia ali estabelecimentos comerciais que lhe eram familiares. A leitura deste ou daquele anúncio fazia surgir diante dos seus olhos, no mesmo instante, um estabelecimento que ele conhecia ou presumia conhecer. Outros anúncios, por outro lado, permaneciam mortos. Não enxergava nada para além das letras impressas.

Ergueu os olhos. No caixa, estava sentada a Fräulein ${ }^{32}$ Magdalene. Pois é, esse era mesmo o nome dela. Era um nome um pouco extraordinário para uma caixa de café. Ele próprio nunca dirigira a palavra a ela. Sempre escutara seu nome unicamente pronunciado pelos empregados de mesa. Lá estava sentada, um pouco gordinha, já não tão jovem assim, ocupada sem cessar. Ele nunca lhe prestara atenção alguma. Agora, de repente, só de vê-la por acaso, ela destacou-se de todos os outros. O café estava bastante repleto, havia pelo menos 60,80 , talvez 100 pessoas. Ele só conhecia o nome de, no máximo, duas ou três. Incompreensível que a tal caixa do café, que sempre the fora indiferente, instantaneamente se tornasse a pessoa mais importante - pelo simples fato de olhar para ela. De todos os outros não sabia nada, não passavam de sombras. Também a sua mulher, os filhos, ninguém significava quase nada em comparação com a Fräulein Magdalene. A única pergunta que restava era qual folhinha atar à Magdalene. Magdalene? Fräulein

\footnotetext{
${ }^{32}$ Vide nota 25 acima.
} 
unmöglich, dieses Kaffee zu verlassen, ehe er sie richtig bezeichnet. Es war beruhigend zu wissen, daß draußen auf einer Tafel das Wort $>$ Park $<$ geschrieben stand. Die ganze Landschaft, durch die er heute gewandert, verschwand wie hinter einem Vorhang. Sie existierte nicht mehr. Er atmete auf, wenn er an die hölzerne Tafel dachte. $>$ Park $<$.

Indes hatte er seinen schwarzen Kaffee ausgetrunken, der Kellner räumte die Tasse mit Schale und Glas fort, die weiße Marmorplatte lag nackt vor ihm. Unwillkürlich nahm er seinen Bleistift und schrieb mit großen Buchstaben auf die Platte: > Tisch $<$. Auch das erleichterte ihn ein wenig. Aber wie viel gab es noch zu tun?

Als er wieder heimkam, waren alle Zettel entfernt, die er an die verschiedenen Gerätschaften befestigt hatte. Seine Frau fragte ihn, was ihm denn eigentlich eingefallen sei. Er fühlte, daß er sie vorläufig nicht einweihen durfte, und sagte, es sei ein Scherz gewesen. Immerhin, es sei doch ein nützlicher Scherz, nicht wahr? Man sollte die Kleinen rechtzeitig daran gewöhnen, von allen Dingen und Menschen auch zu wissen, wie sie heißen. Welche ungeheure Verwirrung war in der Welt. Niemand kennt sich aus.

Nachmittag kam die Schwiegermutter mit der verheirateten Schwägerin $\mathrm{zu}$ Besuch. Während sie drin ihren Kaffee trinken mit Marie (seiner Frau) ${ }^{33}$, benützt er die Gelegenheit, schreibt Zettel, >Schwiegermutter $<$, $>$ Schwägerin $<$ und heftet sie an die Mäntel. Die merkten es
Magdalene? Ou atendente de caixa sentada? Em todo o caso, não conseguiu deixar o café sem denominá-la corretamente. Saber que lá fora havia uma placa com a palavra "Park" deixava-o mais tranquilo. Toda a paisagem pela qual caminhara hoje desaparecera como por detrás de uma cortina. Já não existia mais. Sentia-se aliviado ao pensar na placa de madeira. "Park".

Nisso terminou o café preto, e o empregado retirou a xícara com o bule e o copo. A placa branca de mármore ficou despida em sua frente. Instintivamente apanhou o lápis e escreveu nela, com letras grandes, a palavra "mesa", o que também o deixou algo aliviado. Mas quanto ainda ficou por fazer?

Quando voltou para casa, todos as folhinhas que afixara nos diversos utensílios haviam sido removidas. A mulher perguntoulhe o que é que foi que lhe passara pela cabeça. Sentindo que, por enquanto, ainda não era hora de colocá-la a par da situação, disse que se tratava de uma brincadeira. Afinal, é uma brincadeira útil, não é? Dever-se-ia familiarizar as crianças a tempo com os nomes de todas as coisas e pessoas. Que confusão imensa neste mundo, onde ninguém entende mais nada.

De tarde, estavam de visita a sogra com a cunhada casada. Enquanto tomam café dentro com Marie (a esposa dele), ele aproveita a oportunidade e escreve as palavras "sogra" e "cunhada" em folhinhas, atando-as aos respectivos casacos. Não as notaram quando saíram.

\footnotetext{
${ }^{33}$ Vide nota 16 acima.
} 
nicht, als sie fortgingen.

Am nächsten Morgen versieht er die Kleidungsstücke von Sohn und Tochter, ehe sie in die Schule gehen, mit Zetteln ${ }^{34}$.

Im Geschäft läßt er sich beim Chef melden, macht ihm Vorschläge: überall soll man Zetteln hinspendeln, auch auf die Krawatten zum Beispiel, sogar die Farben muß man bezeichnen. Graue Krawatte, rote, es gibt ja Farbenblinde. Er besteht auch darauf, daß die einzelnen Verkäuferinnen betitelt werden.

Er kommt nach Hause, ist empört, daß alle Zettel wieder entfernt sind. Die Kinder kommen aus der Schule ${ }^{35}$, er ist beruhigt, da er die Zettel, die aus irgendeinem Grunde nicht entfernt wurden, vorfindet.

Indessen hat die Frau den Arzt verständigt. Wie der hereintritt, tritt ihm der Kranke entgegen mit einem Zettel auf der Brust, auf dem mit großen Buchstaben steht: $>$ Ich $<$.
Na manhã seguinte, mune as peças de vestuário do filho e da filha com folhinhas antes de saírem para a escola.

$\mathrm{Na}$ loja, anuncia a sua visita ao chefe, fazendo-lhe propostas: dever-se-ia colocar placas em toda a parte, também, por exemplo, nas gravatas, sendo necessário, inclusive, designar as cores. Gravata cinzenta, vermelha; afinal, há daltônicos. Ademais, insiste em titular cada uma das vendedoras.

Volta para casa, fica indignado ao aperceber-se das folhinhas removidas. As crianças retornam da escola, tranquiliza-se ao encontrar as folhinhas que, por alguma razão, não foram removidas.

Entrementes, a esposa mandou chamar o médico. Ao entrar, o médico depara-se com o doente, em cujo peito há uma folhinha em que está escrito, em letras grandes, "Eu".

Tradução de Alice Leal, Andrea Lauckner, Armin Innerhofer \& Katharina Gschwendner alice.leal@univie.ac.at / alauckner@gmx.at /

armin86@gmx.net / katharina_g@gmx.at

Universidade de Viena

Fonte: Arthur Schnitzler. [1961]. "Ich", in Traumnovelle und andere Erzählungen.

Frankfurt am Main, S. Fischer Verlag GmbH, 2006, 304-311.

\footnotetext{
${ }^{34}$ Vide nota 16 acima.

${ }^{35}$ Vide nota 16 acima.
} 